\title{
Negative Regulators of the Host Response in Sepsis
}

\author{
Annia Maslash-Hubbard, Nidal El-wiher, Thomas P. Shanley and Timothy T. Cornell*
}

Division of Critical Care Medicine, C.S. Mott Children's Hospital at the University of Michigan, Ann Arbor, MI, USA

\begin{abstract}
The inflammatory response of the innate immune system to invading pathogen is complex and requires precise regulation in order to eradicate the organism while protecting the surrounding host tissues. Two main signal transduction pathways, the NF- $\mathrm{BB}$ and mitogen activated protein kinase (MAPK) pathways, are activated by the invading pathogens requiring a set of negative regulatory processes once the pathogen is eradicated. In this review we focus on three key negative regulatory processes: intracellular inhibitors, regulatory phosphatases and epigenetic mechanisms.
\end{abstract}

Keywords: Sepsis, signal transduction, phopshatases, epigenetics, microRNA.

\section{INTRODUCTION}

Our understanding of the mechanisms involved in sepsis have come a long way since Lewis Thomas first proposed the theory that the clinical manifestations of sepsis, the systemic inflammatory response which is secondary to either documented or clinically evident infection, were caused by the host response to the invading organism [1]. The development of therapeutic agents targeting this host response quickly followed our increased understanding of the mediators involved in the pathophysiology of sepsis. Unfortunately, the clinical trials aimed at modulating the host response in sepsis have generally failed [2] , which has refocused efforts on further understanding the regulation of the cellular mechanisms involved in the host's response in order to identify potential therapeutic targets.

The host response in sepsis involves a dysregulation of the inflammatory signaling cascades which leads to an imbalance between pro-inflammatory and anti-inflammatory mediators resulting in an immunologic dissonance [3-7]. This immunologic dissonance is a result of complex interactions of signal transduction pathways triggered by host exposure to pathogen associated molecular patterns (PAMP). These PAMPs bind toll-like receptors (TLR) on the cell surface and utilize a variety of pathways to transmit their signal to the nucleus. The propagation of signals in these pathways rely on interconnected networks of multifunctional, signaling molecules which ultimately elicit a gene expression response that impacts cellular functions [8].

Two primary pathways for signal transduction following TLR activation are the NF- $\mathrm{BB}$ and Mitogen Activated Protein Kinase (MAPK) pathways. Although these two pathways utilize distinct kinases to propagate their signal, common upstream proteins are necessary for the initiation of the intracellular signal following activation of the TLR. TLR

*Address correspondence to this author at the C.S. Mott Children's Hospital, F-6892, University of Michigan Medical School, 1500 East Medical Center Drive, Ann Arbor, MI 48109, USA; Tel: 734-764-5302; Fax: 734-647-5624; E-mail: ttcornel@med.umich.edu activation begins with the binding of the PAMP to a specific TLR which may be enhanced by adaptor proteins such as MyD88 or TRIF. After PAMP binding with or without adaptor protein assistance, the serine/threonine kinase IL-1R associated kinase (IRAK) is recruited to the TLR-PAMP complex and is phosphylorated. Once phosphylorated IRAK is activated and in turn phosphylorates and activates TNF receptor-associated factor 6 (TRAF6). The activated TRAF6 then becomes a key branch point by activating both the NF$\kappa \mathrm{B}$ and MAPK pathways, which lead to transcription and translation of the various proteins involved in the host response [9].

Regulation of the host response occurs at all levels of the signal propogation including: receptor expression and PAMP binding, availability and activity of adaptor proteins, activity of upstream kinases (especially IRAK), activity of the kinases involved in the NF- $\mathrm{KB}$ and MAPK pathways as well as the transcription and translation of the response genes. A detailed description of the regulation of all of these steps is beyond the scope of this review. Instead, we will focus on those negative regulators of the signal transduction pathways that have been implicated in sepsis and directly impact inflammatory gene expression with specific emphasis on those regulators that seem to hold promise for developing novel therapeutic strategies. Our focus will include the inducible intracellular inhibitors, the regulatory phosphatases and recent evidence implicating epigenetic regulatory mechanisms which are involved in controlling the host response as they relate to innate immunity.

\section{INDUCIBLE INTRACELLULAR INHIBITORS}

Several intracellular inhibitors are involved in the regulation of TLR signaling $[10,11]$, however only three intracellular inhibitors, IRAK-M, supressors of cytokine signaling (SOCS) proteins and A20, have been shown to be induced by TLR activation. These three intracellular inhibitors are of special interest in sepsis because they provide negative feedback regulation of the upstream portion of TLR signaling and their loss of function is associated with a dysregulation in the production of host inflammatory mediators. 
IRAK-M is a member of the IRAK family and is predominantly expressed in monocytes and macrophages [12-14]. IRAK ${ }^{-/}$mice demonstrate enhanced production of IL-12, IL-6 and TNF- $\alpha$ in response to LPS stimulation [12]. Unlike other members of the IRAK family, IRAK-M has no kinase activity and the exact mechanism by which IRAK-M regulates TLR signaling has not been fully delineated. IRAK-M does not prevent the association of IRAK1 with the TLR complex but may prevent the disassociation of the TLR/IRAK complex to limit activation of TRAF6 [11]. Recent evidence suggests an additional role for IRAK-M which may be to stabilize other negative regulators, specifically the dual specific phosphatase MKP-1, thereby enhancing the down regulation of TLR signaling [15].

IRAK-M's role in the negative feed back loop for TLR signaling is also noted by its requirement for endotoxin tolerance. Macrophages isolated from IRAK-M ${ }^{-/}$mice were not tolerized by low dose LPS and had adequate cytokine production upon restimulation with high dose LPS [12]. IRAK-M levels in isolated human monocytes are also rapidly elevated in an ex vivo model of endotoxin tolerance following the restimulation dose of LPS [16]. Monocytes isolated from septic patients or patients receiving an intravenous endotoxin challenge also exhibit high levels of IRAK-M and decreased cytokine production to ex vivo LPS stimulation [16, 17]. Thus, IRAK-M appears to be a key member of the endogenous system aimed at regulating PAMP-triggered inflammation.

A second inducible inhibitor of TLR signaling is the family of SOCS proteins. Eight SOCS proteins have been identified each being induced by a variety of cytokines as well as PAMPS (e.g. LPS) [18]. SOCS negatively regulate TLR signaling by functioning as an E3 ubiquitin ligase to promote the degradation of proteins involved in or by directly inhibiting kinases within the signaling pathways [18]. As it relates to TLR signaling SOCS 1 is the best studied proteins in this class.

SOCS $1^{-/}$mice are hyper-responsive to LPS challenge resulting in increased serum levels of TNF- $\alpha$ as well as increased mortality $[19,20]$. Macrophages isolated from these mice show impairment of endotoxin tolerance related to an increased activation of both $\mathrm{p} 38$ and JNK $[19,20]$. The SOCS $1^{-/-}$macrophages also show increased TNF- $\alpha$, IL-12 and NO production following LPS stimulation when compared to WT macrophages [18]. Similar to IRAK-M, these data support the role of SOCS 1 as a negative regulator of TLR signaling pathways.

A20 is a third inducible enzyme that appears to regulate the host response by providing a negative feedback loop for NF- $\kappa B$ activation [21]. NF- $\kappa B$ activation leads to the induction of A20 and once expressed, it can negatively regulate ongoing NF- $\mathrm{KB}$ expression [22]. This regulation of $\mathrm{NF}-\kappa \mathrm{B}$ by $\mathrm{A} 20$ occurs through a unique ubiquitin-editing function in which A20 has both peptidase and ligase activity [23]. A $20^{-/}$mice show enhanced inflammatory response and sustained NF- $\kappa$ B activity in response to TNF- $\alpha$ [24] as well as the requirement of A20 for the termination of TLR signaling [25]. Together, these observations suggest inducible, negative regulators of cytokines could be targeted for subsequent drug development.

\section{PHOSPHATASES AS REGULATORS}

In addition to the induction of intracellular proteins following TLR activation, several phosphatases are activated, which also negatively regulate the host response. Phosphatases act by removing a phosphate group from serine, threonine or tyrosine residues reducing the activity of the target enzyme. The kinases involved in the inflammatory pathways, NF- $\mathrm{kB}$ and MAPK, are activated through phosphyloration by upstream kinases and are thus prime targets for phosphatase regulation.

Phosphatases are divided into two major classes based on the amino acid residues they dephosphorylate with several families in each class (Table 1). Two families of phosphatases, the serine/threonine phosphatase and the dual specific phosphatases, appear important in the regulation of the host response.

\section{Protein Serine/Threonine Phosphatases}

Nearly 30 catalytic subunits of the protein serine/threonine phosphatases have been identified based on their amino acid sequence of the catalytic subunit [26]. The serine/threonine phosphatase, protein phosphatase 2A (PP2A), is one of the more important regulators of the host inflammatory response.

PP2A has many roles in the regulation of cellular processes but its regulation of the NF-KB and MAP kinase signaling pathways is important for limiting the host response. The role of PP2A as a regulator of the NF- $\mathrm{\kappa B}$ pathway is well established. Initially, data using purified proteins suggested that PP2A negatively regulated I kappa kinase (IKK), the central kinase in the NF-KB pathway [27]. However, more recently investigations showed that PP2A forms a stable complex with IKK and that in the settings of PP2A inhibition (with OA or fostriecin), the degradation of I $\mathrm{B}$ was attenuated thus suggesting PP2A is a positive regulator of the NF- $\kappa B$ pathway [28].

A broader role for PP2A in regulating the MAPK pathway is also well established. Studies using a human acute monocytic leukemia cell line, THP-1 cells, show that the PP2A co-percipitated with JNK. When these cells were treated with the phosphatase inhibitor okadiac acid (OA) JNK kinase activity and AP-1 transciptional activity increased resulting in increased IL-1 $\beta$ expression [29]. The regulation of the $\mathrm{p} 38$ MAPK pathway by PP2A has also been established [30-33] and this has been shown to involve stabilization of mRNA by altering tristetraprolin (TTP) binding to the 3' untranslated regions of unstable transcripts [33]. Delineating the role of PP2A in regulating the host response in vivo is the goal of ongoing studies within our laboratory.

\section{Dual Specific Phosphatases (DUSP)}

The dual specific phosphatases (DUSPs) have the unique characteristics of being able to dephosphylorate both phosphothreonine and phosphotyrosine residues. Thirty genes that code for DUSP have been identified in the human genome [34]. A subfamily of the DUSPs, the MAPK Phosphates (MKPs), are important regulators of the MAPK pathway and are further divided by their subcellular localization (Table 2). 
Table 1. Classes of Phosphatases

\begin{tabular}{|c|c|}
\hline Serine/Threonine Phosphatases & Tyrosine Phosphatases \\
\hline$\underline{\text { PPP Family }}$ & $\underline{\text { Class I cysteine-based PTP }}$ \\
\hline PP1 & "Classical" PTPs \\
\hline PP2A & Receptor-like PTP \\
\hline PP2B & CD45 \\
\hline PP4 & RPTP $\alpha$ Cytosolic PTPs \\
\hline$\underline{\text { PPM Family }}$ & Nonreceptor PTP \\
\hline \multirow[t]{11}{*}{$\mathrm{PP} 2 \mathrm{C}$} & SHP-1 \\
\hline & SHP-2 \\
\hline & PTP1B \\
\hline & $\begin{array}{l}\text { Dual-Specificity } \\
\text { Phosphatases }\end{array}$ \\
\hline & MKP-1 \\
\hline & MKP-2 \\
\hline & MKP-3/Pyst1 \\
\hline & $\underline{\text { Class II cysteine-based PTP }}$ \\
\hline & Low-Molecular Weight PTP's \\
\hline & $\underline{\text { Class III cysteine-based PTP }}$ \\
\hline & $\mathrm{CDC} 25$ \\
\hline
\end{tabular}

*Modified from Shanley TP Crit Care Med 2002; 30: S80-S88.

As regulators of the MAP kinase pathways the MKPs add flexibility and specificity to the inflammatory response by 1) having different kinetics of induction of MKPs in response to different stimuli, 2) varying subcellular compartmentalization of the phosphatases and thus the regulatory processes, 3) differentially expressing in various cell types involved in the inflammatory response, and 4) by mediating cross-talk between the different MAPK pathways [35]. To date eleven MKPs have been identified of which three, MKP-1, PAC-1, and MKP-5 have been shown to be key in regulation of the innate immune response.

\section{MKP-1(DUSP-1)}

MKP-1 is a $39.5 \mathrm{kDa}$ nuclear phosphatase that predominately dephosphylates p38 and JNK. It has been shown to be a negative regulator of macrophage function in response to LPS, LTA, heat and osmotic shock, ultraviolet radiation and heat-inactivated $S$. aureus [36-41]. Also, recent studies involving $\mathrm{MKP}-1^{-/}$mice confirmed the negative regulatory role of MKP-1 in animal models of sepsis [4144]. When compared to WT mice, the $\mathrm{MKP}-1^{-/-}$mice had elevated levels of pro-inflammatory cytokines and increased mortality. MKP-1 ${ }^{--}$mice developed septic shock with multisystem organ dysfunction in response to lower doses of LPS when compared to WT mice [41]. In addition, there was an attenuation of IL-10 levels produced in $\mathrm{MKP}-1^{-/-}$mice as well as isolated macrophages [41, 42]. The alteration in
Table 2. Classification of Dual Specific Phosphatases

\begin{tabular}{|c|c|}
\hline Subgroup & Phosphatases \\
\hline \hline Nuclear & MKP-1 \\
\hline & PAC-1 \\
\hline & MKP-2 \\
\hline Cytoplasmic & hVH3 \\
\hline & MKP-3 \\
\hline & MKP-X \\
\hline & MKP-7 \\
\hline Nuclear and Cytoplasmic & hVH5 \\
\hline & MKP-4 \\
\hline & MKP-5 \\
\hline
\end{tabular}

cytokine response was mediated through the p38 MAPK pathway [36-38, 40-42].

\section{MKP-5 (DUSP-10)}

MKP-5 is a $52.6 \mathrm{kDa}$ phosphatase that also primarily dephosphorylates JNK and p38 [45, 46] and has a role in not only regulating the inflammatory host response but may also play a role in connecting the innate and adaptive immune responses [47]. Macrophages from $\mathrm{MKP}-5^{-/}$mice release more TNF and IL-6 in response to LPS, peptidoglycan and poly I: C [48]. T-cell activation was also increased in MKP$5^{-/-}$mice when compared to wild-type animals but the T-cells had reduced proliferation [48]. In addition, MKP-5 regulates INF- $\gamma$ and IL-4 production by Th1 and Th2 cells [48]. These studies illustrate the importance of MKP-5 in the complex regulation of the interaction between innate and adaptive immunity.

\section{$P A C-1$ (DUSP-2)}

PAC-1 is a $32 \mathrm{kDa}$ phosphatase that is expressed only in hematopoietic cells [49]. Unlike the negative regulatory role of MKP-1 and MKP-5, PAC-1 has a positive regulatory role in the host response [50]. PAC- $1^{-/-}$macrophages show reduced production of the pro-inflammatory cytokines IL-6, IL-12, IL-1 $\beta$ and TNF- $\alpha$ [50]. The reduced cytokines are a result of decreased transcription factor activation mediated by JNK/ERK cross-talk [50]. Additional cross-talk between PAC-1 and other DUSPs as a contributing factor for the positive regulation has not been completely addressed [49]. These data indicate a key regulatory role for the DUSPs of the host response following PAMP stimulation.

\section{EPIGENETIC PROCESSES AS REGULATORS}

Epigenetics refers to those heritable changes in genomic function that are not passed on through changes in DNA sequences [51]. The role of epigenetic changes in regulating the host response to disease has only recently been investigated. Although the complete regulation processes are not completely understood, several lines of evidence suggest a key role for epigenetic processes. The two epigenetic 


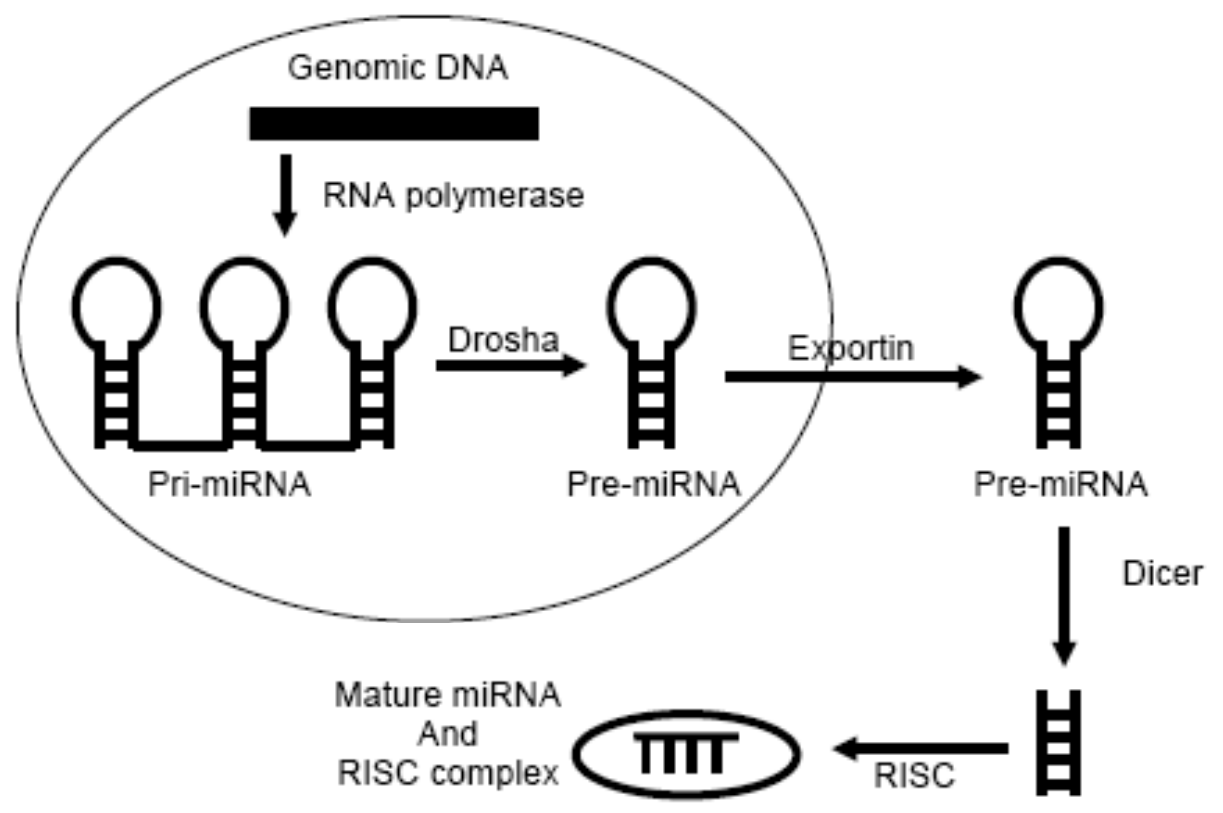

Fig. (1). Processing of miRNA. Primary-microRNA (pri-miRNA) is transcribed from genomic DNA by RNA polymerase. The RNAse complex Drosha then cleaves Pri-miRNA to pre-miRNA which is exported from the nucleus by the transport complex Exportin. Once in the cytoplasm pre-miRNA is further processed by the Dicer enzyme complex into mature miRNA and loaded into the RNA-induced silencing complex (RISC) where it combines with target mRNA resulting in degradation or repression of the target mRNA.

mechanisms of regulation that seem important in the host response are histone modifications and microRNA.

\section{Histone Modifications}

Epigenetic modifications of chromatin structure play a crucial role in controlling gene expression though the role of these modifications play in regulating the host response in sepsis are just beginning to be investigated. Eukaryotic DNA is wound around an octomer of histone proteins $(\mathrm{H} 2 \mathrm{~A}, \mathrm{H} 2 \mathrm{~B}$, $\mathrm{H} 3$, H4), forming a nucleosome and must be unwound to allow transcription to occur. The chromatin remodeling complexes (CRCs) which are recruited to promoter sites by bound transcription factors or modified histones are responsible for unwinding the DNA and exposing promoter sequences [52]. These histone modifications include methylation, phosphyloration and acetylation and have been linked to the regulation of the host inflammatory response [52]. Inhibition of histone deacetylase enzymes results in the reduced production of TNF- $\alpha$ and nitric oxide [53] as well as IL-10 [54] production in response to cellular stimulation. Histone deacetlyase inhibitors have also been shown to decrease the activation of macrophages and dendritic cells resulting in an imbalanced between Th1 and Th2 cells [55]. Histone methylation is involved in the suppression of cytokine production in endotoxin tolerance $[56,57]$. Wen et al. showed that histone modifications regulate the dendritic cell production of IL-12 resulting in long-term immunosuppression [58]. Thus several lines of evidence suggest a regulatory role for histone modifications in response to the inflammatory response to pathogens.

\section{microRNA}

MicroRNAs are small (approximately 22 nucleotides) strands of RNA that regulate cellular processes at the post- transcriptional level. They are transcribed from endogenous non-coding regions of the genome into primary-miRNA complexes. Drosha, an RNAse, then cleaves the primarymiRNA into shorter stem-loop complexes termed premiRNA [59]. Pre-miRNA is transported from the nucleus to the cytoplasm by the transport proteins of the Exportin 5 complex where they are again processed by the Dicer enzyme complex into mature-miRNA [60]. The mature miRNA are loaded into the RNA-induced silencing complex (RISC) [59] where they combine with target mRNA resulting to the degradation or repression of the target mRNA [59] (Fig. 1).

Several microRNAs have recently been shown to not only be induced in response to TLR ligands but also regulate the signal pathways involved in the host inflammatory response. Expression profiling of human monocytes revealed increases in $\mathrm{miR}-146 \mathrm{a} / \mathrm{b}, \mathrm{miR}-132$ and $\mathrm{miR}-155$ in response to LPS [61]. Further studies of these three miRNAs indicated that miR-146 negatively regulated the response to LPS through down regulation of IRAK 1 and TRAF 6 [61]. IL-1 $\beta$ signaling is also negatively regulated by miR-146 regulating the production of both IL-8 and RANTES in lung alveolar epithelial cells [62]. Additionally, miR-155 was also found to be induced by TLR 2, 3, 4 and 9 lingands as well as TNF$\alpha$ suggesting a broad acting role for miR-155 in the innate inflammatory host response [63]. In a mouse model of sepsis, miR-155 and mir-125b were both induced in response to LPS [64] and studies in transgenic mice lacking functional miR-155 suggest a negative regulatory role for miR-155 in response to LPS [64]. Although the exact mechanisms by which microRNAs regulate the host inflammatory response are not clearly defined, several lines of evidence are establishing their importance as a negative regulatory agent. 


\section{SUMMARY}

The regulation of the host inflammatory response is complex and occurs at several points along signal transduction pathways. The roles of key endogenous regulators including intracellular inhibitors, the regulatory phosphatases, and epigenetic regulatory mechanisms are just starting to be understood. As our understanding of these regulatory elements increases, new targeted therapies will hopefully improve our ability to manipulate these regulatory processes allowing us to achieve "perfect" balance in the host inflammatory response and ameliorates the organ injury associated with immunologic dissonance

\section{REFERENCES}

[1] Thomas L. Germs. N Engl J Med 1972; 287(11): 553-5.

[2] Abraham E. Why immunomodulatory therapies have not worked in sepsis. Intensive Care Med 1999; 25(6): 556-66.

[3] Abraham E, Singer M. Mechanisms of sepsis-induced organ dysfunction. Crit Care Med 2007; 35(10): 2408-16.

[4] Bone RC. Sir Isaac Newton, sepsis, SIRS, and CARS. Crit Care Med 1996; 24(7): 1125-8.

[5] Hotchkiss RS, Karl IE. The pathophysiology and treatment of sepsis. N Engl J Med 2003; 348(2): 138-50.

[6] Oberholzer A, Oberholzer C, Minter RM, Moldawer LL. Considering immunomodulatory therapies in the septic patient: should apoptosis be a potential therapeutic target? Immunol Lett 2001; 75(3): 221-4.

[7] Rittirsch D, Flierl MA, Ward PA. Harmful molecular mechanisms in sepsis. Nat Rev Immunol 2008; 8(10): 776-87.

[8] Cornell TT, Shanley TP. Signal transduction overview. Crit Care Med 2005; 33(12 Suppl): S410-3.

[9] Takeda K, Kaisho T, Akira S. Toll-like receptors. Annu Rev Immunol 2003; 21: 335-76.

[10] Han J, Ulevitch RJ. Limiting inflammatory responses during activation of innate immunity. Nat Immunol 2005; 6(12): 1198205.

[11] Liew FY, Xu D, Brint EK, O'Neill LA. Negative regulation of tolllike receptor-mediated immune responses. Nat Rev Immunol 2005; 5(6): 446-58.

[12] Kobayashi K, Hernandez LD, Galan JE, Janeway CA, Jr., Medzhitov R, Flavell RA. IRAK-M is a negative regulator of Tolllike receptor signaling. Cell 2002; 110(2): 191-202.

[13] Rosati O, Martin MU. Identification and characterization of murine IRAK-M. Biochem Biophys Res Commun 2002; 293(5): 1472-7.

[14] Wesche H, Gao X, Li X, Kirschning CJ, Stark GR, Cao Z. IRAK$\mathrm{M}$ is a novel member of the Pelle/interleukin-1 receptor-associated kinase (IRAK) family. J Biol Chem 1999; 274(27): 19403-10.

[15] Su J, Xie Q, Wilson I, Li L. Differential regulation and role of interleukin-1 receptor associated kinase- $M$ in innate immunity signaling. Cell Signal 2007; 19(7): 1596-601.

[16] Escoll P, del Fresno C, Garcia L, et al. Rapid up-regulation of IRAK-M expression following a second endotoxin challenge in human monocytes and in monocytes isolated from septic patients. Biochem Biophys Res Commun 2003; 311(2): 465-72.

[17] van 't Veer C, van den Pangaart PS, van Zoelen MA, et al. Induction of IRAK-M is associated with lipopolysaccharide tolerance in a human endotoxemia model. J Immunol 2007; 179(10): 7110-20.

[18] Yoshimura A, Naka T, Kubo M. SOCS proteins, cytokine signalling and immune regulation. Nat Rev Immunol 2007; 7(6): 454-65.

[19] Kinjyo I, Hanada T, Inagaki-Ohara K, et al. SOCS1/JAB is a negative regulator of LPS-induced macrophage activation. Immunity 2002; 17(5): 583-91.

[20] Nakagawa R, Naka T, Tsutsui H, et al. SOCS-1 participates in negative regulation of LPS responses. Immunity 2002; 17(5): 67787.

[21] Coornaert B, Carpentier I, Beyaert R. A20: Central gatekeeper in inflammation and immunity. J Biol Chem 2009; 284(13): 8217-21.

[22] Krikos A, Laherty CD, Dixit VM. Transcriptional activation of the tumor necrosis factor alpha-inducible zinc finger protein, A20, is mediated by kappa B elements. J Biol Chem 1992; 267(25): 179716.
[23] Wertz IE, O'Rourke KM, Zhou H, et al. De-ubiquitination and ubiquitin ligase domains of A20 downregulate NF-kappaB signalling. Nature 2004; 430(7000): 694-9.

[24] Lee EG, Boone DL, Chai S, et al. Failure to regulate TNF-induced NF-kappaB and cell death responses in A20-deficient mice. Science 2000; 289(5488): 2350-4.

[25] Boone DL, Turer EE, Lee EG, et al. The ubiquitin-modifying enzyme A20 is required for termination of Toll-like receptor responses. Nat Immunol 2004; 5(10): 1052-60.

[26] Cohen PTW. Overview of Protein Serine/Threonine Phosphatases. In: Arino J, Alexander DR, Eds. Protein Phosphatases. New York: Springer 2004; pp. 1-20.

[27] DiDonato JA, Hayakawa M, Rothwarf DM, Zandi E, Karin M. A cytokine-responsive IkappaB kinase that activates the transcription factor NF-kappaB. Nature 1997; 388(6642): 548-54.

[28] Kray AE, Carter RS, Pennington KN, et al. Positive regulation of IkappaB kinase signaling by protein serine/threonine phosphatase 2A. J Biol Chem 2005; 280(43): 35974-82.

[29] Shanley TP, Vasi N, Denenberg A, Wong HR. The serine/threonine phosphatase, PP2A: endogenous regulator of inflammatory cell signaling. J Immunol 2001; 166(2): 966-72.

[30] Avdi NJ, Malcolm KC, Nick JA, Worthen GS. A role for protein phosphatase-2A in p38 mitogen-activated protein kinase-mediated regulation of the c-Jun $\mathrm{NH}(2)$-terminal kinase pathway in human neutrophils. J Biol Chem 2002; 277(43): 40687-96.

[31] Boudreau RT, Conrad DM, Hoskin DW. Apoptosis induced by protein phosphatase $2 \mathrm{~A}(\mathrm{PP} 2 \mathrm{~A})$ inhibition in $\mathrm{T}$ leukemia cells is negatively regulated by $\mathrm{PP} 2 \mathrm{~A}$-associated p38 mitogen-activated protein kinase. Cell Signal 2007; 19(1): 139-51.

[32] Boudreau RT, Hoskin DW, Lin TJ. Phosphatase inhibition potentiates IL-6 production by mast cells in response to FcepsilonRI-mediated activation: involvement of p38 MAPK. J Leukoc Biol 2004; 76(5): 1075-81.

[33] Sun L, Stoecklin G, Van Way S, et al. Tristetraprolin (TTP)-14-3-3 complex formation protects TTP from dephosphorylation by protein phosphatase $2 \mathrm{a}$ and stabilizes tumor necrosis factor-alpha mRNA. J Biol Chem 2007; 282(6): 3766-77.

[34] Alonso A, Sasin J, Bottini N, et al. Protein tyrosine phosphatases in the human genome. Cell 2004; 117(6): 699-711.

[35] Lang R, Hammer M, Mages J. DUSP meet immunology: dual specificity MAPK phosphatases in control of the inflammatory response. J Immunol 2006; 177(11): 7497-504.

[36] Chen P, Hutter D, Yang X, Gorospe M, Davis RJ, Liu Y Discordance between the binding affinity of mitogen-activated protein kinase subfamily members for MAP kinase phosphatase-2 and their ability to activate the phosphatase catalytically. J Biol Chem 2001; 276(31): 29440-9.

[37] Nimah M, Zhao B, Denenberg AG, et al. Contribution of MKP-1 regulation of $\mathrm{p} 38$ to endotoxin tolerance. Shock 2005; 23(1): 80-7.

[38] Shepherd EG, Zhao Q, Welty SE, Hansen TN, Smith CV, Liu Y The function of mitogen-activated protein kinase phosphatase-1 in peptidoglycan-stimulated macrophages. J Biol Chem 2004; 279(52): 54023-31.

[39] Wang J, Shen WH, Jin YJ, Brandt-Rauf PW, Yin Y. A molecular link between E2F-1 and the MAPK cascade. J Biol Chem 2007; 282(25): 18521-31.

[40] Wu JJ, Bennett AM. Essential role for mitogen-activated protein (MAP) kinase phosphatase-1 in stress-responsive MAP kinase and cell survival signaling. J Biol Chem 2005; 280(16): 16461-6.

[41] Zhao Q, Wang X, Nelin LD, et al. MAP kinase phosphatase 1 controls innate immune responses and suppresses endotoxic shock. J Exp Med 2006; 203(1): 131-40.

[42] Chi H, Barry SP, Roth RJ, et al. Dynamic regulation of pro- and anti-inflammatory cytokines by MAPK phosphatase 1 (MKP-1) in innate immune responses. Proc Natl Acad Sci USA 2006; 103(7): 2274-9.

[43] Hammer M, Mages J, Dietrich H, et al. Dual specificity phosphatase 1 (DUSP1) regulates a subset of LPS-induced genes and protects mice from lethal endotoxin shock. J Exp Med 2006; 203(1): 15-20.

[44] Salojin KV, Owusu IB, Millerchip KA, Potter M, Platt KA, Oravecz T. Essential role of MAPK phosphatase-1 in the negative control of innate immune responses. J Immunol 2006; 176(3): 1899-907. 
[45] Tanoue T, Moriguchi T, Nishida E. Molecular cloning and characterization of a novel dual specificity phosphatase, MKP-5. J Biol Chem 1999; 274(28): 19949-56.

[46] Theodosiou A, Smith A, Gillieron C, Arkinstall S, Ashworth A. MKP5, a new member of the MAP kinase phosphatase family, which selectively dephosphorylates stress-activated kinases. Oncogene 1999; 18(50): 6981-8.

[47] Salojin K, Oravecz T. Regulation of innate immunity by MAPK dual-specificity phosphatases: knockout models reveal new tricks of old genes. J Leukoc Biol 2007; 81(4): 860-9.

[48] Zhang Y, Blattman JN, Kennedy NJ, et al. Regulation of innate and adaptive immune responses by MAP kinase phosphatase 5 . Nature 2004; 430(7001): 793-7.

[49] Liu Y, Shepherd EG, Nelin LD. MAPK phosphatases--regulating the immune response. Nat Rev Immunol 2007; 7(3): 202-12.

[50] Jeffrey KL, Brummer T, Rolph MS, et al. Positive regulation of immune cell function and inflammatory responses by phosphatase PAC-1. Nat Immunol 2006; 7(3): 274-83.

[51] Probst AV, Dunleavy E, Almouzni G. Epigenetic inheritance during the cell cycle. Nat Rev Mol Cell Biol 2009; 10(3): 192-206.

[52] Foster SL, Medzhitov R. Gene-specific control of the TLR-induced inflammatory response. Clin Immunol 2009; 130(1): 7-15.

[53] Choi Y, Park SK, Kim HM, et al. Histone deacetylase inhibitor KBH-A42 inhibits cytokine production in RAW 264.7 macrophage cells and in vivo endotoxemia model. Exp Mol Med 2008; 40(5): $574-81$.

[54] Villagra A, Cheng F, Wang HW, et al. The histone deacetylase HDAC11 regulates the expression of interleukin 10 and immune tolerance. Nat Immunol 2009; 10(1): 92-100.

[55] Brogdon JL, Xu Y, Szabo SJ, et al. Histone deacetylase activities are required for innate immune cell control of Th1 but not Th2 effector cell function. Blood 2007; 109(3): 1123-30.
[56] Chan C, Li L, McCall CE, Yoza BK. Endotoxin tolerance disrupts chromatin remodeling and NF-kappaB transactivation at the IL1beta promoter. J Immunol 2005; 175(1): 461-8.

[57] El Gazzar M, Yoza BK, Hu JY, Cousart SL, McCall CE. Epigenetic silencing of tumor necrosis factor alpha during endotoxin tolerance. J Biol Chem 2007; 282(37): 26857-64.

[58] Wen H, Dou Y, Hogaboam CM, Kunkel SL. Epigenetic regulation of dendritic cell-derived interleukin-12 facilitates immunosuppression after a severe innate immune response. Blood 2008; 111(4): 1797-804.

[59] Carthew RW, Sontheimer EJ. Origins and mechanisms of miRNAs and siRNAs. Cell 2009; 136(4): 642-55.

[60] Lau PW, Macrae IJ. The molecular machines that mediate microRNA maturation. J Cell Mol Med 2009; 13(1): 54-60.

[61] Taganov KD, Boldin MP, Chang KJ, Baltimore D. NF-kappaBdependent induction of microRNA miR-146, an inhibitor targeted to signaling proteins of innate immune responses. Proc Natl Acad Sci USA 2006; 103(33): 12481-6.

[62] Perry MM, Moschos SA, Williams AE, Shepherd NJ, LarnerSvensson HM, Lindsay MA. Rapid changes in microRNA-146a expression negatively regulate the IL-1beta-induced inflammatory response in human lung alveolar epithelial cells. J Immunol 2008; 180(8): 5689-98.

[63] O'Connell RM, Taganov KD, Boldin MP, Cheng G, Baltimore D. MicroRNA-155 is induced during the macrophage inflammatory response. Proc Natl Acad Sci USA 2007; 104(5): 1604-9.

[64] Tili E, Michaille JJ, Cimino A, et al. Modulation of miR-155 and miR-125b levels following lipopolysaccharide/TNF-alpha stimulation and their possible roles in regulating the response to endotoxin shock. J Immunol 2007; 179(8): 5082-9.

Received: June 07, 2011

Revised: June 16, 2011

Accepted: June 18, 2011

(C) Maslash-Hubbard et al.; Licensee Bentham Open.

This is an open access article licensed under the terms of the Creative Commons Attribution Non-Commercial License (http: //creativecommons.org/licenses/by-nc/3.0/) which permits unrestricted, non-commercial use, distribution and reproduction in any medium, provided the work is properly cited. 